Revista de

Contabilidade e

Organizações

www.rco.usp.br
DOI: http://dx.doi.org/10.11606/issn.1982-6486.rco.2018.142534
Journal of

Accounting and

Organizations

www.rco.usp.br

\title{
O efeito da família no comportamento financeiro de adolescentes em escolas públicas
}

The effect of the family on the financial behavior of adolescents in public schools

Cristian Baú Dal Magro; ${ }^{\mathrm{a}}$ Marcello Christiano Gorla ${ }^{\mathrm{b}}$; Tarcísio Pedro da Silva ${ }^{\mathrm{b}}$; Nelson Hein ${ }^{\mathrm{b}}$

${ }^{a}$ Universidade Comunitária da Região de Chapecó

${ }^{b}$ Universidade Regional de Blumenau

\section{Palavras-chave}

Família na educação financeira.

Comportamento financeiro.

Ensino público.

\section{Resumo}

O estudo analisa o efeito da interação da família no comportamento financeiro de adolescentes em escolas da rede pública de ensino. A educação financeira e suas consequências no comportamento futuro de adultos têm origem na infância e adolescência. Foi aplicado questionário em cerca de 1.900 alunos do ensino médio de 14 escolas públicas na região Sul do país. Os resultados indicam que o comportamento típico de falta de controle dos gastos e a baixa propensão à poupança estão relacionados com uma menor discussão do tema em família. De modo geral, a família exerce importante papel em disseminar o conhecimento financeiro inicial, ou este se dá em situações cotidianas.
Keywords

Family in financial education.

Financial behavior.

Public education.
Informações do Artigo

Recebido: 22 de janeiro de 2018

Aceito: 17 de dezembro de 2018

Publicado: 24 de dezembro de 2018

\begin{abstract}
The study analyzes the effect of family interaction on the financial behavior of adolescents in public schools. Financial education and its consequences on future adult behavior originate in childhood and adolescence. A questionnaire was applied to about 1,900 high school students from 14 public schools in the South of Brazil. The results indicate that the typical behavior of having no control of spending and the low propensity to saving are related to a weak discussion of this issue by the family. In general, the family disseminate initial financial knowledge or through daily experiences.
\end{abstract}

\section{Implicações práticas}

Educadores e gestores públicos responsáveis por políticas públicas de educação podem se interessar pelos resultados que mostram o baixo nível de educação financeira em adolescentes de escolas públicas em Blumenau e região. Para estes adolescentes a família seria a fonte predominante de educação para o consumo e poupança. Porém, mesmo as famílias, sobretudo de baixa renda, devem ser conscientizadas nestas questões.

Copyright (C) 2018 FEA-RP/USP. Todos os direitos reservados

\section{INTRODUÇ̃̃O}

No Brasil, a educação financeira não tem sido parte integrante do ambiente escolar, ou mesmo familiar (Pires et al., 2013). Ao mesmo tempo em que houve um aumento significativo na participação dos adolescentes na economia pelo aumento no poder de compra, também ocorreu endividamento financeiro (Fernandes \& Candido, 2014).O acesso facilitado ao crédito, pelos incentivos governamentais com juros reduzidos, o aumento no consumo das famílias, além do eventual endividamento das famílias, estão associados ao nível de educação financeira de pais e adolescentes. Essa temática ganha força internacionalmente, e está associada à formação geral da sociedade.

Agradecimentos

Agradecemos o apoio do Conselho Nacional de Desenvolvimento Científico e Tecnológico (CNPq) e da Fundação Fritz Miller.

Autor Correspondente: Tel. (49) 3346-3060

E-mail: crisbau@unochapeco.edu.br (C. B. Dal Magro); gorlacontabil@yahoo.com.br (M. C. Gorla); tarcisio@furb.br (T. P. da Silva); hein@furb.br (N. Hein) Universidade Comunitária da Região de Chapecó. Rua Servidão Anjo da Guarda, 295-D - Efapi - Chapecó/SC - 89809-900, Brasil. 
A promoção da educação financeira começa durante a infância, ao acompanhar os pais em supermercados e lojas em geral, e observar a troca de dinheiro por bens, mercadorias e serviços (Bowen, 2002; Denegri, Palavecinos, Ripoll \& Yáñez, 1999; Shim, Barber, Card, Xiao \& Serido, 2010; Bessa, Fermiano \& Coria, 2014). Apesar da aprendizagem financeira continuar ao longo de toda a vida, as primeiras lições dos anos de desenvolvimento cognitivo perduram nas atitudes da fase adulta (Bowen, 2002). A adolescência também é um momento crítico de treinamento para a gestão dos recursos financeiros. Adolescentes não apreciam a poupança (Alhabeeb, 1996), e nesta na fase denominada "riqueza prematura", os gastos supérfluos induzem um planejamento financeiro limitado (O'Neill, 1992).

Entre os determinantes da educação financeira no decorrer da formação de crianças, jovens e adolescentes, estão as condições socioeconômicas e demográficas de jovens (Mandell \& Klein, 2007), o papel das escolas (Savoia, Saito \& Santana, 2007; Cole, Paulson \& Shastry, 2015), mas também a condição financeira das famílias (Lusardi, Mitchell \& Curto, 2010; Clarke, Heaton, Israelsen \& Eggett, 2005). Tais determinantes ajudariam na formação de uma cultura para poupança e conscientização em relação ao sistema financeiro. Especificamente no caso da família, os valores financeiros dos adolescentes e de seus pais são bastante semelhantes (Pritchard e Myers, 1992). E estas condições afetam, por exemplo, o conhecimento básico sobre taxas de juros, inflação e diversidade de riscos, assim como o uso adequado do dinheiro (Lusardi, Mitchell e Curto, 2010). Outros estudos mostram que gênero, idade, experiência profissional e cursos em temas associados ao uso do dinheiro também afetam a alfabetização financeira dos adolescentes (exemplo é Chen e Volpe, 1998). Por fim, no contexto da rede pública de ensino, em geral famílias de baixa renda possuem maior dificuldade na administração de seus recursos (Lusardi e Mitchell, 2011, Heckman e Grable, 2011, Potrich et al., 2015; Miotto e Parente, 2015).

O governo brasileiro desenvolveu iniciativas para a inclusão da educação financeira nas escolas e ações com o público-alvo adulto. Entre elas, a Estratégia Nacional de Educação Financeira (ENEF), instituída pelo Decreto ${ }^{0}$ 7.397/2010. Contudo, as ações não estão plenamente aplicadas nas escolas da rede pública de ensino. A não aplicação das ações abre espaço para analisar o impacto isolado da família na educação financeira de adolescentes.

A presente pesquisa seleciona a região de Blumenau em Santa Catarina, em que as escolas públicas não inserem disciplinas ou temas de finanças pessoais no currículo escolar dos jovens. Dessa forma, isola um provável efeito da escola no desenvolvimento do entendimento financeiro dos jovens, ao analisar o efeito do papel da família e das interações no comportamento para poupança dos adolescentes dessas escolas. Foram aplicados questionários em 14 escolas do ensino médio da região, acessando 1.937 jovens entre 14 e 20 anos. Na cidade de Blumenau, já foi identificado por Silva, Dal Magro, Gorla e Nakamura (2017) um baixo nível de conhecimento financeiro de uma amostra de cerca de 4,6 mil alunos de 14 escolas públicas de ensino médio. O presente estudo amplia a análise para cidades em torno desse município, e além do baixo nível de educação já detectada, analisa o papel da família no comportamento financeiro dos adolescentes.

De maneira geral, ensinar as crianças a serem financeiramente alfabetizadas tem sido quase sempre função dos pais, mas muitos desses pais não têm as habilidades e o conhecimento necessários (Jorgensen \& Savla, 2010). O comportamento de poupança é relevante na educação (Lucci, Zerrenner, Verrone \& Santos, 2006) sobretudo em famílias de baixa renda que para conseguirem poupar pequenas quantias, necessitam de acesso a informações e desenvolvimento de habilidades que propiciem um melhor manejo do dinheiro (Cardozo, 2011). Ainda, além do fator família, o círculo social desses jovens poderia auxiliar ou prejudicar o processo de educação financeira.

A escola formal poderia atuar como interveniente no processo de ensino, aprimorando os conhecimentos financeiros adquiridos na família e no círculo social para melhoria na alfabetização financeira dos adolescentes. Os resultados desse estudo apontam que, na ausência de uma formação curricular, o desenvolvimento de uma cultura de poupança depende essencialmente do papel da família na vida desse adolescente, e outras influências sociais. Portanto, para reduzir os efeitos da ausência da atuação da família na questão, sugere-se a remodelagem curricular para incluir a educação da gestão financeira pessoal. 


\section{O PAPEL DA FAMÍlIA NA EDUCAÇÃO FINANCEIRA, NO CONSUMO CONSCIENTE E NA POUPANÇA}

Conforme a Organização de Cooperação e de Desenvolvimento Econômico - OECD (2013), a educação financeira é o processo de melhoria no entendimento dos indivíduos sobre conceitos e produtos financeiros. Por meio de informação, instrução e aconselhamento, tais indivíduos desenvolvem habilidades na administração dos seus recursos financeiros. Em geral, as pessoas não possuem conhecimento financeiro adequado para decidir sobre suas finanças pessoais (Braunstein \& Welch, 2002; Perry, 2008). A análise da formação financeira em uma vertente pessoal (e não profissional) depende da compreensão de como as decisões das famílias são afetadas pelas circunstâncias econômicas (Worthington, 2006). Esse conhecimento financeiro pessoal é baixo no Brasil (Vieira, Bataglia \& Serei, 2011), seja por razões culturais e históricas de um passado inflacionário (Vieira, Bataglia \& Serei, 2011), seja por fatores psicológicos que afetam a decisão de poupar ou consumir (Cardozo, 2011).

O baixo nível de poupança decorre de falta de conhecimento sobre finanças pessoais, das restrições de recursos pelas dívidas já contraídas pelo indivíduo ou pela família, mas também pelo desconforto com a ideia de investir e abrir mão da satisfação dos desejos imediatos. Por outro lado, indivíduos com maior grau de educação financeira seriam menos propensos a sustentar padrões de consumo incompatíveis com sua renda (Cardozo, 2011).

A escola poderia contribuir para implantar uma nova cultura financeira, sobretudo, para os jovens que estão no momento de desenvolvimento de suas habilidades (Robb, 2011). Os programas de educação financeira propiciam aos adolescentes uma visão de poupança e melhoria nas decisões financeiras (Mandell, 2005). A escola deveria trabalhar com temas que auxiliem o futuro cidadão a conhecer e gerenciar suas necessidades cotidianas, porém temas como comércio, economia, impostos e finanças não são tratados (Martins, 2004). Essa função seria exercida, sobretudo, pela rede pública de ensino (Oehler \& Werner, 2008; Bessa et al., 2014).

Os pais, também desempenham um papel importante na socialização financeira dos filhos (Jorgensen \& Savla, 2010; Lusardi et al., 2010). A Tabela 1 apresenta um resumo dos estudos anteriores que retratam o papel da família e outros fatores sociais como determinantes da educação financeira. O papel da família tem sido um fator preponderante para a formação de adolescentes conscientes sobre investimentos, poupança, consumo e seguridade social (educação financeira). A forma como a juventude aprende questões financeiras também varia e é provável que seja uma combinação de estratégias intencionais e não intencionais usadas pelos adultos (Bowen, 2002). O comportamento dos pais ao discutir questões financeiras com as crianças e a sua orientação para um consumo consciente e poupança impactam no comportamento financeiro dos filhos na idade adulta (Webley \& Nyhus, 2006). As crianças aprendem sobre finanças por meio da instrução deliberada, da prática e da observação (Clarke et al., 2005). Mesmo que alguns adolescentes considerem que seus pais "não sabem de nada", como costumam dizer, os jovens reconhecem habilidades financeiras de seus pais (Bowen, 2002).

Além do efeito da escola e da família, outros efeitos sobre comportamento financeiro de adolescentes são estudados. Por exemplo, Chen e Volpe $(1998,2002)$ diagnosticaram diferenças na alfabetização financeira de acordo com o gênero, a idade, a experiência profissional e de cursos associados a finanças pessoais. Apesar do efeito de gênero ainda não ser consenso, alguns estudos mostram que o gênero feminino comparativamente tem menor educação financeira (Chen \& Volpe 1998, 2002; Mandell, 2008; Lusardi et al., 2010; Jang, Hahn \& Park, 2014). Por fim, a socialização pelos meios de comunicação (televisão, rádio, revistas, etc.) e conversas com colegas, profissionais e ambiente de trabalho (Bowen, 2002) também contribuem para o desenvolvimento dos adolescentes em questão de finanças. 
Tabela 1. Estudos sobre o papel da família e de outros aspectos sociais como determinantes da educação financeira

\begin{tabular}{|c|c|c|c|c|}
\hline Autores & Nível de ensino & Amostra e Idade & País & Contribuições no âmbito da Educação Financeira \\
\hline Chen e Volpe (1998) & Ensino superior & 924 & Estados Unidos & $\begin{array}{l}\text { Os universitários do gênero feminino, classe social baixa, com idade inferior a } 30 \\
\text { anos, e com pouca experiência profissional possuem menores níveis de alfabetização } \\
\text { financeira. }\end{array}$ \\
\hline Eitel e Martin (2009) & Ensino superior & $\begin{array}{c}204 \\
\text { Acima de } 17 \text { anos }\end{array}$ & Estados Unidos & $\begin{array}{l}\text { Baixa alfabetização financeira; e, apesar de perceberem esta necessidade, os indivíduos } \\
\text { não atuam para aprimorar a profissionalização financeira. Idade e etnia dos estudantes } \\
\text { foram preditores da educação financeira. }\end{array}$ \\
\hline Lusardi (2007) & Todos os níveis & $\begin{array}{c}890 \\
\text { Acima de } 18 \text { anos }\end{array}$ & Estados Unidos & $\begin{array}{l}\text { Mulheres, negros, hispânicos e com menor nível educacional apresentaram menor nível } \\
\text { de educação financeira, mesmo as pessoas com maior nível de ensino universitário. }\end{array}$ \\
\hline Shim et al. (2010) & Ensino superior & $\begin{array}{l}2.098 \\
15 \text { a } 18 \text { anos }\end{array}$ & $\begin{array}{l}\text { Hispânicos, asiáticos/ } \\
\text { asiáticos americanos/ } \\
\text { nativos americanos }\end{array}$ & $\begin{array}{l}\text { A família tem papel substancialmente mais efetivo comparado à experiência } \\
\text { profissional na educação financeira. A socialização financeira precoce está relacionada } \\
\text { ao aprendizado financeiro, e ao comportamento financeiro efetivo. }\end{array}$ \\
\hline Kim e Chatterjee (2013) & Todos os níveis & $\begin{array}{l}628 \\
17 \text { a } 21 \text { anos }\end{array}$ & Estados Unidos & $\begin{array}{l}\text { As experiências de socialização na infância melhoram as práticas financeiras } \\
\text { e a posse de bens dos entrevistados na idade adulta. Os entrevistados que tinham } \\
\text { contas bancárias e cujos gastos financeiros eram monitorados pelos pais na infância } \\
\text { apresentaram maior probabilidade para a posse de ativos financeiros e de atitudes mais } \\
\text { positivas sobre finanças pessoais na idade adulta. }\end{array}$ \\
\hline Bessa et al. (2014) & Ensino médio & $\begin{array}{c}830 \\
10 \text { a } 15 \text { anos }\end{array}$ & Brasil & $\begin{array}{l}\text { A geração atual (entre } 10 \text { e } 15 \text { anos) carece de compreensões sobre economia. A } \\
\text { família pouco se envolve no processo de socialização econômica, e possui socialização } \\
\text { econômica insuficiente para lidar com as exigências econômicas atuais. }\end{array}$ \\
\hline Cameron et al. (2014) & Ensino médio & $\begin{array}{c}335 \\
15 \text { a } 18 \text { anos }\end{array}$ & Nova Zelândia & $\begin{array}{l}\text { A educação financeira é menor entre os estudantes mais pobres, com menor capacidade } \\
\text { em gramática e matemática. A alfabetização financeira começando pelo ensino médio } \\
\text { pode ser a chave para a melhoria na tomada de decisão financeira da população. }\end{array}$ \\
\hline Potrich, Vieira e Kirsch (2015) & Todos os níveis & $\begin{array}{c}1.067 \\
\text { Acima de } 18 \text { anos }\end{array}$ & Brasil & $\begin{array}{l}\text { Os indivíduos do gênero masculino, sem dependentes, com maior escolaridade e renda } \\
\text { familiar têm maior capacidade de decidir sobre investimento, poupança e seguridade } \\
\text { social, o que reduziria inadimplência e levaria à maior qualidade de vida familiar. }\end{array}$ \\
\hline
\end{tabular}




\section{PROCEDIMENTOS METODOLÓGICOS E DADOS}

Foi aplicado um questionário in loco em 14 escolas da rede pública de cidades da região de Blumenau no Sul do Brasil, que atualmente reúne cerca de 4,6 mil alunos de ensino médio e profissionalizante. Nas cidades dessa região as escolas públicas não inserem disciplinas ou temas de finanças pessoais no currículo escolar dos jovens. Assim, a escolha dessa região específica permite isolar um provável efeito da escola no desenvolvimento do entendimento financeiro dos jovens, e observar apenas o efeito do papel da família na educação financeira e no comportamento para poupança dos jovens.

Os pesquisadores obtiveram, formalmente, o acesso à direção das escolas com apoio da Secretaria de Estado do Desenvolvimento Regional de Blumenau (SDR/GERED-Blumenau). Ao longo do segundo semestre do ano de 2015 foram obtidas 1.937 respostas de alunos entre 14 e 20 anos de idade (taxa de resposta de 41\%). A taxa de resposta reflete $\mathrm{o}$ fato de turmas que não responderam à pesquisa pois estavam em provas ou em processo de recuperação de conteúdo.

O questionário é composto por questões de caracterização, como gênero; nível de ensino; idade; renda e moradia, e 9 (nove) questões relativas ao papel exercido pela família, o comportamento de poupança e o conhecimento financeiro do adolescente. As questões, que podem ser visualizadas na Tabela 2, têm escalas categóricas, que pareceu adequado ao tipo de respondente e contexto da pesquisa. Em todos as 6 dimensões, as categorias mais altas utilizadas em cada questão da escala significam a maior presença da família.

Primeiro, o papel exercido pela família foi captado por 6 questões, as questões tratam da necessidade de justificar o uso do dinheiro para a família (prestar contas), nível de diálogo na hora de decidir sobre uma compra na família (diálogo), frequência em que há conversas sobre dinheiro com os pais (frequência), os assuntos financeiros que são perguntados ou aconselhados junto à família (assunto), se a família figura entre os meios que o jovem usa para adquirir tal conhecimento (referência), e a decisão sobre o que fazer com o dinheiro (autonomia). O comportamento ou propensão para a poupança foi captado pelo objetivo com que o jovem administra seus próprios recursos (objetivo) e sobre seu perfil de poupança (perfil). Por fim, foi abordado o que ele próprio pensa sobre seu nível de conhecimento financeiro autodeclarado (conhecimento). O instrumento de pesquisa foi validado preliminarmente em uma turma de 30 alunos do ensino médio.

Para a análise dos resultados foi utilizada a estatística descritiva e análise fatorial para determinar o peso das questões de cada grupo. Posteriormente, foi possível estabelecer a variável de mensuração do papel da família e do comportamento para poupança. Na sequência, foi utilizado agrupamento (cluster) e teste de média para captar os efeitos do papel da família no comportamento para poupança. Por fim, foram elaborados testes de diferenças de médias para determinar a existência de diferenças entre o papel da família e o comportamento para poupança; entre o gênero e o comportamento para poupança; e entre o gênero e o conhecimento financeiro

Como se observa na Tabela 2, os respondentes se dividem em duas faixas de idade (14 e 16 anos, e entre 17 e 20 anos), sendo $52 \%$ do gênero feminino, e com uma renda familiar entre $\mathrm{R} \$ 0,79$ e $\mathrm{R} \$ 2,36$ mil mensais. Interessante notar que $90,55 \%$ dos respondentes reside com seus pais, e pequena parcela reside com outros familiares e ou sozinhos. Essa condição configura o potencial da análise do papel da família de baixa renda na educação financeira dos jovens (Lusardi \& Mitchell, 2011; Heckman \& Grable, 2011; Lizote \& Verdinelli, 2014; Potrich et al., 2015; Miotto \& Parente, 2015). 
Tabela 1. Estatística descritiva da caracterização dos respondentes

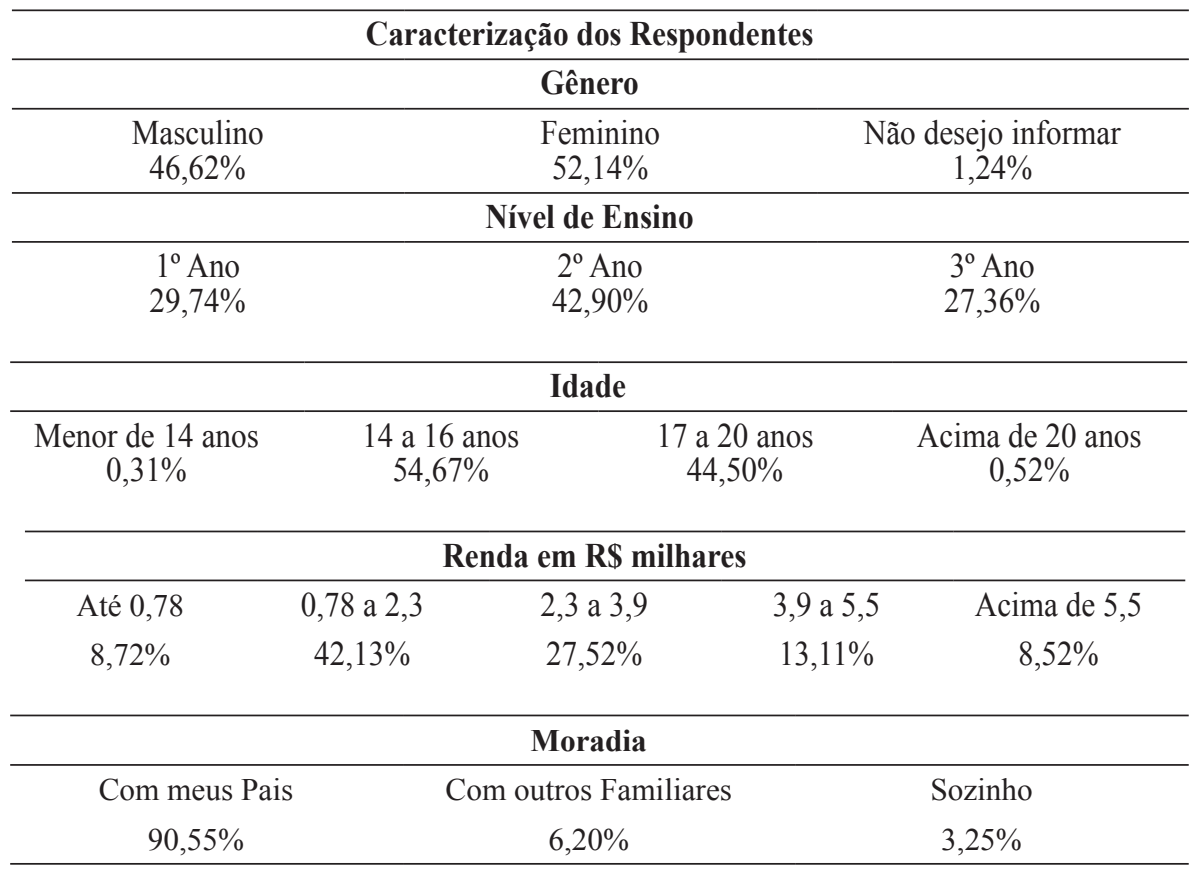

Fonte: Elaborado pelos autores.

A interação dos adolescentes com a família, em geral, tem passado distante dos assuntos que envolvem conhecimentos financeiros. Independente de como obtém o dinheiro, ao morarem com os pais existe algum grau de dependência deles em relação aos pais.

A Tabela 3 apresenta a distribuição dos respondentes nas diversas perguntas do questionário aplicado. Quase $40 \%$ dos estudantes da amostra não explicam ou justificam aos pais o uso que fazem do dinheiro, apenas $23 \%$ declaram ter obrigação de prestar contas de como usam o dinheiro. Ao menos metade dos alunos parece ter sua opinião considerada quanto a família decide sobre a compra de um produto para o uso da família, mas isso não significa necessariamente o uso de conhecimento financeiro, mas apenas uma interação maior sobre o uso do recurso familiar. Nestas famílias, a conversa sobre dinheiro varia desde uma forma regular, até a ausência completa ( $23 \%$ dos casos). Essa mesma situação foi notada por Mori e Lewis (2001), em que apenas 32\% dos pais estavam preocupados em conversar e orientar os filhos à educação financeira. Contudo, outro ponto que chama a atenção é que em $21 \%$ dos casos, o assunto é tratado diariamente, o que pode não ser uma questão de educação, mas de prestação de contas de um orçamento dedicado para certas questões, as quais ficam sob a responsabilidade do adolescente ou para sua subsistência diária.

O assunto financeiro mais tratado no ambiente familiar está centrado no consumismo e uso consciente do dinheiro (questões de gasto), que de alguma forma é associado à poupança. Parte dedicada à estudo e carreira, ou sobre possibilidades de renda futura. Contudo, o assunto que envolve os investimentos (longo prazo) é pouco tratado, o que pode estar associado também à baixa formação dos pais, e a baixa renda familiar observada na maioria dos respondentes.

A fonte de aprendizado predominante dos temas financeiros é a família (45\%). Lembramos que nesta região as escolas não oferecem atividades ou matérias específicas de educação financeira no currículo, o que talvez explique a baixa atuação da escola (9\%). Contudo, mesmo as interações extra sala na interação com colegas não seja relevante, dada baixa influência de amigos (2,5\%). Por outro lado, indicam que as situações e experiências cotidianas vividas no dia-a-dia (25\%) no convívio social importam. A grande maioria ou decide sozinho, ou compartilha internamente na família (ou cônjuge), mostrando uma forte influência da família quando desejam ou podem partilhar a decisão. 
Tabela 3. Estatística descritiva sobre o papel da família e das interações na educação financeira

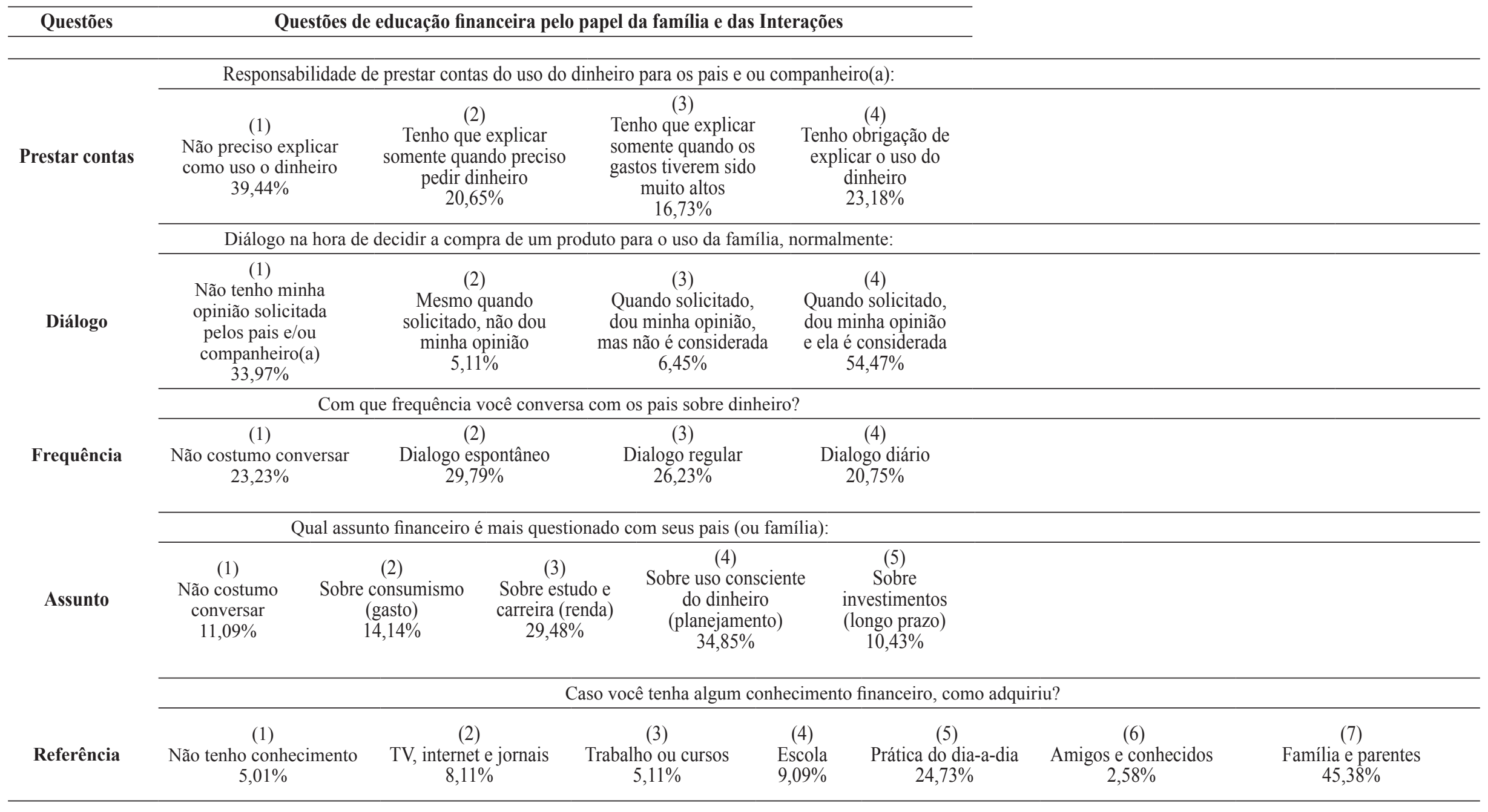


Tabela 3. Estatística descritiva sobre o papel da família e das interações na educação financeira (continuação)

\begin{tabular}{|c|c|c|c|c|c|}
\hline Questões & & uestões de educação & anceira pelo papel da & mília e das Interações & \\
\hline \multirow[b]{2}{*}{ Autonomia } & \multicolumn{5}{|c|}{ Como decido o que fazer com meu dinheiro? } \\
\hline & $\begin{array}{c}(1) \\
\text { Não recebo dinheiro } \\
3,82 \%\end{array}$ & $\begin{array}{c}(2) \\
\text { Decido sozinho } \\
56,07 \%\end{array}$ & $\begin{array}{c}(3) \\
\text { Conversando com } \\
\text { outras pessoas } \\
3,46 \%\end{array}$ & $\begin{array}{c}(4) \\
\text { Conversando com os } \\
\text { pais ou cônjuge } \\
33,56 \%\end{array}$ & $\begin{array}{c}(5) \\
\text { Meus pais decidem } \\
\text { como devo gastar } \\
3,10 \%\end{array}$ \\
\hline \multicolumn{6}{|c|}{ Em relação à forma de administrar meus recursos financeiros, costumo: } \\
\hline Objetivo & $\begin{array}{l}\text { (1) } \\
\text { Não costumo } \\
\text { guardar dinheiro } \\
27,16 \%\end{array}$ & $\begin{array}{l}(2) \\
\text { Guardar parte dos } \\
\text { recursos, porém sem } \\
\text { planos futuros } \\
15,85 \%\end{array}$ & $\begin{array}{c}(3) \\
\text { Guardar parte dos } \\
\text { recursos para gastar } \\
\text { conforme planejado } \\
37,89 \%\end{array}$ & $\begin{array}{l}(4) \\
\text { Guardar e investir } \\
\text { parte de meus } \\
\text { rendimentos } \\
19,10 \%\end{array}$ & \\
\hline \multirow{3}{*}{ Perfil } & \multicolumn{5}{|c|}{ Em relação ao meu perfil financeiro, me considero: } \\
\hline & $\begin{array}{c}(1) \\
\text { Desligado (a), não } \\
\text { tenho controle sobre } \\
\text { meus gastos } \\
6,35 \%\end{array}$ & $\begin{array}{c}(2) \\
\text { Gastador (a), gasto } \\
\text { praticamente tudo } \\
\text { que ganho } \\
22,72 \%\end{array}$ & $\begin{array}{c}(3) \\
\text { Conservador (a), não } \\
\text { me arrisco a ganhar } \\
\text { mais } \\
10,33 \%\end{array}$ & $\begin{array}{c}(4) \\
\text { Cauteloso (a), faço } \\
\text { compras somente } \\
\text { quando necessário } \\
41,77 \%\end{array}$ & $\begin{array}{c}(5) \\
\text { Poupador (a), evito } \\
\text { gastar minhas } \\
\text { economias } \\
18,84 \%\end{array}$ \\
\hline & \multicolumn{5}{|c|}{ Como considera seu nível de conhecimento financeiro: } \\
\hline Conhecimento & $\begin{array}{c}(1) \\
\text { Ruim } \\
5,63 \%\end{array}$ & $\begin{array}{c}(2) \\
\text { Regular } \\
33,14 \%\end{array}$ & $\begin{array}{c}(3) \\
\text { Bom } \\
45,07 \%\end{array}$ & $\begin{array}{c}\text { (4) } \\
\text { Muito Bom } \\
10,64 \%\end{array}$ & $\begin{array}{l}(5) \\
\text { Ótimo } \\
5,52 \%\end{array}$ \\
\hline
\end{tabular}

Fonte: Elaborado pelos autores.

Nota: Questões e dimensões: Papel da Família e das Interações: prestar contas, diálogo, frequência, assunto, referência, autonomia. Comportamento de polpação: Objetivo e Perfil. Conhecimento financeiro autodeclarado: conhecimento. 
Em relação aos hábitos de consumo e poupança, cerca de $30 \%$ dos respondentes declaram não ter qualquer preocupação com poupança. Dos que economizam, a maior parte tem certo planejamento mas não o associa com uma busca por investimento, o que mostra um conhecimento e comportamento financeiro restrito à gastos e equilíbrio orçamentário, mas não de aplicação financeira de recursos. Essa falta de estratégia de investimentos, para Halfeld (2006), é oriunda da incapacidade de gestão financeira pessoal que impede os indivíduos de acumularem valores e bens no longo prazo. O baixo grau de poupança está associado à uma menor consciência financeira (Bessa et al., 2014, Lusardi e Mitchell, 2007, Fernandes e Candido, 2014). Cerca de metade deles indica que é conservador ou cauteloso, e não se veem como 'poupadores'.

Quando à percepção dos estudantes a respeito do quanto conhecem sobre o assunto, apenas $15 \%$ diz ter um conhecimento financeiro muito bom. Mesmo com a tendência da resposta autodeclarada elevar as chances de indicarem os pontos mais altos da escala, ainda 40\% deles declaram ter um conhecimento satisfatório ou ruim. Os adolescentes de certa forma reconhecem que não possuem um conhecimento financeiro adequado para a tomada das decisões que envolve as finanças pessoais do dia a dia, momento que destaca a necessidade de auxílio na tomada de decisão.

\section{DISCUSSÃO DOS RESULTADOS}

Para testar a influência do papel da família no comportamento para poupança dos adolescentes, foi realizada uma análise de agrupamento - cluster (Tabela 4), usando as 6 dimensões captadas para o papel da família (Prestar Contas, Diálogo, Frequência, Assunto, Referência e Autonomia).

Tabela 4. Análise de grupamento para influência do papel da família na educação financeira

\begin{tabular}{rccccccccc}
\hline & \multicolumn{3}{c}{$\begin{array}{c}\text { Grupo 1 }=592 \\
\text { Influência Moderada da } \\
\text { família }\end{array}$} & \multicolumn{3}{c}{$\begin{array}{c}\text { Grupo 2 } \mathrm{n}=704 \\
\text { Maior influência } \\
\text { da família }\end{array}$} & & \multicolumn{2}{c}{$\begin{array}{c}\text { Grupo } 3 \mathrm{n}=641 \\
\text { Nenhuma influência } \\
\text { da família }\end{array}$} \\
\hline & Média & Mediana & D.P. & Média & Mediana & D.P. & Média & Mediana & D.P. \\
\cline { 2 - 10 } Prestar Contas & 1,755 & 1,0 & 0,958 & 3,108 & 3,0 & 1,055 & 1,724 & 1,0 & 0,974 \\
Diálogo & 3,042 & 4,0 & 1,323 & 3,156 & 4,0 & 1,269 & 2,215 & 1,0 & 1,375 \\
Frequência & 2,872 & 3,0 & 0,901 & 2,886 & 3,0 & 0,941 & 1,569 & 1,0 & 0,734 \\
Assunto & 3,786 & 4,0 & 0,826 & 3,584 & 4,0 & 0,877 & 2,218 & 2,0 & 1,027 \\
Referência & 4,606 & 5,0 & 1,880 & 6,079 & 7,0 & 1,485 & 5,076 & 5,0 & 1,991 \\
Autonomia & 2,318 & 2,0 & 0,802 & 3,585 & 4,0 & 0,896 & 2,264 & 2,0 & 0,849 \\
Total & $\mathbf{3 , 0 6 3}$ & $\mathbf{3 , 1 6 7}$ & $\mathbf{0 , 4 2 7}$ & $\mathbf{3 , 7 3 3}$ & $\mathbf{3 , 6 6 7}$ & $\mathbf{0 , 3 8 7}$ & $\mathbf{2 , 5 1 1}$ & $\mathbf{2 , 6 6 7}$ & $\mathbf{0 , 5 1 4}$ \\
\hline
\end{tabular}

Fonte: Elaborado pelos autores.

O grupo 2 gerado pela análise de grupamento reúne os adolescentes que possuem a maior influência da família na educação financeira. O grupo se destaca pelo habito/necessidade de prestar contas dos gastos, ter a família como referência de discussão sobre o assunto, e por uma menor autonomia em como gastar o dinheiro (em geral conversam com os pais antes de gastar o dinheiro). Contudo, o grupo 1 e 2 são similares na questão do diálogo (diálogo, frequência do diálogo e o assunto tratado). Enquanto estes grupos ocorre um diálogo frequente em torno de consumismo e renda, no grupo 3 mesmo a família sendo a referência para o assunto, o diálogo é raro ou nunca ocorre. No grupo 3 praticamente a família é ausente no tema, e sendo ela a principal referência pode-se dizer que estes jovens podem estar sem qualquer fonte de educação financeira. No grupo 2, além da presença no diálogo e prestação de contas, a discussão sobre os gastos é maior (menor autonomia).

Pelo teste de média (Tabela 5), comparamos o nível de poupança entre os indivíduos do grupo 2 (maior influência da família) com os demais indivíduos (grupos 1 e 3, de influência moderada ou nenhuma influência da família). Testes adicionais ANOVA entre os grupos são apresentados no Apêndice. 
A presença da família na educação financeira está relacionada tanto com o objetivo percebido pelos jovens para a poupança, quanto com o perfil que eles se atribuem. Os perfis mais propensos à poupança (guarda recursos) e perfis de consumo conversador aparecem, mas a presença da família não é suficiente para suscitar a poupança com o objetivo de aplicação e obtenção de rendimentos financeiros. Essa limitação pode estar associada à própria fonte da educação, pais de menor poder aquisitivo, talvez estejam replicando seus próprios objetivos para poupança. O que reflete uma limitação que poderia ser vencida pela atuação de disciplinas formais na escola.

Tabela 5. Comportamento para poupança pela influência da família

\begin{tabular}{ccccccc}
\hline & $\begin{array}{c}\text { Influência } \\
\text { da família }\end{array}$ & Média & Mediana & D.P. & Teste t. Sig. & $\begin{array}{c}\text { Teste Mann- } \\
\text { Whitney }\end{array}$ \\
\hline \multirow{2}{*}{ Objetivo (Poupança) } & 0 & 2,425 & 3,000 & 1,0898 & $0,022^{*}$ & $0,001^{*}$ \\
& 1 & 2,602 & 3,000 & 1,0659 & & $0,000^{*}$ \\
\hline
\end{tabular}

Fonte: Elaborado pelos autores.

Nota: 0 - amostra dos respondentes caracterizados, pela análise de grupamento, como tendo influência moderada ou nenhuma influência da família na educação financeira (grupo 1 e grupo 3); 1 - amostra dos respondentes caracterizados por uma maior influência da família na educação financeira. * significância ao nível de $5 \%$.

Diversas tabelas de distribuição comparativa por gênero, idade, série escolar e se os jovens moram com os pais são apresentados no Apêndice, as diferenças encontradas são sutis ou inexistentes

Observa-se uma maior frequência de conversa com os pais sobre dinheiro no caso das meninas, assim como a necessidade de justificar o uso do dinheiro. Porém, as meninas ouvem seus pais mais a respeito de carreira (renda) e o uso consciente do dinheiro (gasto), enquanto meninos tendem a questionar mais suas famílias sobre investimentos (longo prazo). Meninas adquirem conhecimento sobre educação financeira em geral com família e parentes, enquanto meninos também ouvem amigos, ambiente de trabalho e mídia. Assim, a família parece ser mais presente na educação financeira das meninas. Elas tendem a guardar e investir os rendimentos, contudo são conversadoras. As diferenças entre gêneros tanto para objetivo quanto perfil são muito frágeis nas amostras comparadas pela mediana (Teste Mann-Whitney).

Tabela 6. Comportamento para poupança e Conhecimento financeiro e o gênero dos adolescentes

\begin{tabular}{ccccccc}
\hline & Gênero & Média & Mediana & D.P. & Teste t. Sig. & $\begin{array}{c}\text { Teste Mann- } \\
\text { Whitney }\end{array}$ \\
\hline \multirow{2}{*}{ Objetivo (Poupança) } & 0 & 2,478 & 3,000 & 1,059 & $0,038^{*}$ & 0,562 \\
Perfil (Poupança) & 1 & 2,499 & 3,000 & 1,106 & & 0,201 \\
Conhecimento & 0 & 3,483 & 4,000 & 1,188 & $0,032^{*}$ & 0,128 \\
\hline
\end{tabular}

Fonte: Elaborado pelos autores.

Nota: 0 - masculino; 1 - feminino. * significância ao nível de 5\%.

Já em relação ao conhecimento a diferença de médias desaparece, indicando que de forma geral os adolescentes, independente de gênero, têm uma percepção similar em relação ao que conhecem da matéria. Como mencionado, eles próprios se atribuem um conhecimento em geral limitado. 
Outros efeitos que podem ser vistos no Apêndice são idade e faixa escolar. A idade dos respondentes pode explicar um relaxamento na obrigatoriedade de prestar contas de seus gastos aos pais ou companheiro, assim como uma menor frequência de diálogos com os pais sobre o que será feito com o dinheiro. Em relação à série escolar, o avanço dos alunos no ensino médio faz com que as famílias criem maior confiança para tratarem sobre diferentes temas financeiros. Assim, nos anos iniciais as famílias discutem com os adolescentes sobre consumismo, posteriormente, com o avanço no ensino passam a tratar de investimentos, e no terceiro ano do ensino médio discutem sobre estudo e carreira, visto que é um importante momento para a decisão profissional dos adolescentes. Por fim, adolescentes que moram com os pais tem maior interação com os mesmos, mostrando o efeito da estrutura e formação da família na questão.

\section{CONCLUSÕES}

A região analisada é formada por escolas que não tratam da educação financeira em seus currículos, e um baixo nível de educação financeira dos adolescentes. Os alunos têm adquirido conhecimento financeiro com pais e parentes, e não na escola. Porém, o diálogo no ambiente familiar sobre o assunto financeiro é restrito em geral à poupança e consumismo.

Os resultados dessa pesquisa sugerem que na ausência de uma formação curricular, o desenvolvimento de uma cultura de poupança pode depender, essencialmente, do papel da família na vida desse adolescente, e outras influências sociais (Jorgensen e Savla, 2010, Lusardi et al., 2010; Shim et al., 2010). Na amostra analisada, na predominância da família como fonte de orientação financeira, o nível de conhecimento e o perfil de poupança são limitados nos jovens, o que sugere a necessidade de atuação da escola. No presente estudo, apenas $9 \%$ dos jovens consideram que a escola é a origem de seus conhecimentos financeiros. Estes resultados indicam a necessidade da reflexão da obrigatoriedade da educação financeira na grade curricular do ensino básico (tramitando no congresso nacional). A Estratégia Nacional de Educação Financeira (ENEF), iniciada em 2010 não tem sido amplamente adotado, dado seu caráter voluntário. As recomendações do programa se fossem largamente adotadas poderiam favorecer a interação entre a matemática escolar e a educação financeira em sala de aula (Hofmann e Moro, 2013).

Um ponto não tratado no artigo é o nível e conteúdo da educação financeira dos pais. Como já mostrado na literatura, os valores sobre poupança e uso do dinheiro de adolescentes e de seus pais são semelhantes (Pritchard e Myers, 1992; Bowen, 2002). Assim, a educação financeira dos pais pode moldar o tipo de conhecimento passado, os exemplos em casa, os conselhos e recomendações dadas. Se o conhecimento financeiro é adquirido também dos pais, pode ser particularmente benéfico envolver pais e parentes com reduzida formação acadêmica ou que não sejam financeiramente experientes em ações do ENEF.

Por fim, discutimos também o efeito de gênero, idade e série. Apesar das diferenças de gênero no comportamento financeiro não serem tão marcantes quando as dos estudos de Chen e Volpe (1998), Chen e Volpe (2002), Mandell (2008), Lusardi et al. (2010) e Jang, Hahn e Park (2014), os efeitos da idade e da série escolar podem ser úteis para o desenho dos programas de educação financeira formal nas escolas.

\section{REFERÊNCIAS}

Alhabeeb, M. J. (1996). Teenagers' money, discretionary spending and saving. Journal of Financial Counseling and Planning, 7, 123.

Bessa, S., Fermiano, M. B., \& Coria, M. D. (2014). Student's economic comprehension between 10 and 15 years old. Psicologia \& Sociedade, 26(2), 410-419. DOI: http://dx.doi.org/10.1590/S0102-71822014000200017.

Bowen, C. F. (2002). Financial knowledge of teens and their parents. Journal of Financial Counseling and Planning, 13(2), 93.

Braunstein, S., \& Welch, C. (2002). Financial literacy: An overview of practice, research, and policy. Federal Reserve Bulletin, 88, 445.

Cameron, M. P., Calderwood, R., Cox, A., Lim, S., \& Yamaoka, M. (2014). Factors associated with financial literacy among high school students in New Zealand. International Review of Economics Education, 16, 1221. DOI: https://doi.org/10.1016/j.iree.2014.07.006.

Cardozo, J. D. S. (2011). Um olhar sobre a Estratégia Nacional de Educação Financeira-ENEF e sua potencial contribuição para a disseminação da cultura previdenciária. Trabalho de Conclusão de Curso. Licenciatura em Pedagogia. Universidade de Brasília (UnB). 
Chen, H., \& Volpe, R. P. (1998). An analysis of personal financial literacy among college students. Financial Services Review, 7(2), 107-128. DOI: https://doi.org/10.1016/S1057-0810(99)80006-7.

Chen, H., \& Volpe, R. P. (2002). Gender differences in personal financial literacy among college students. Financial Services Review, 11(3), 289.

Clarke, M. D., Heaton, M. B., Israelsen, C. L., \& Eggett, D. L. (2005). The acquisition of family financial roles and responsibilities. Family and Consumer Sciences Research Journal, 33, 321 - 340. DOI: https://doi. org/10.1177/1077727X04274117.

Cole, S., Paulson, A., \& Shastry, G. K. (2015). High school curriculum and financial outcomes: The impact of mandated personal finance and mathematics courses. Journal of Human Resources, 30, 7-31. DOI: https:// doi.org/10.3368/jhr.51.3.0113-5410R1.

Denegri, M., Palavecinos, M., Ripoll, M., \& Yáñez, V. (1999). Caracterización psicológica del consumidor de la IX Región. Consumir para Vivir y no Vivir para Consumir, 7-31.

Eitel, S. J., \& Martin, J. (2009). First-Generation Female College Students' financial Literacy: Real and Perceived Barriers to Degree Completion. College Student Journal, 43(2), 616-630.

Fernandes, A. H. S, \& Candido, J. G. (2014). Educação Financeira e nível do endividamento: Relato de pesquisa entre os estudantes de uma instituição de ensino da cidade de São Paulo. Revista Eletrônica Gestão e Serviços, 5(2), 894-913.

Heckman, S. J., \& Grable, J. E. (2011). Testing the role of parental debt attitudes, student income, dependency status, and financial knowledge have in shaping financial self-efficacy among college students. College Student Journal, 45(1), 51.

Hofmann, R. M., \& Moro, M. L. F. (2013). Educação matemática e educação financeira: perspectivas para a ENEF. Zetetiké: Revista de Educação Matemática, 20(38), 37-54. DOI: https://doi.org/10.20396/zet.v20i38.8646609.

Jang, K., Hahn, J., \& Park, H. J. (2014). Comparison of financial literacy between Korean and US high school students. International Review of Economics Education, 16, 22-38. DOI: https://doi.org/10.1016/j. iree.2014.07.003.

Kim, J., \& Chatterjee, S. (2013). Childhood financial socialization and young adults' financial management. Journal of Financial Counseling and Planning, 24(1), 61-79.

Lucci, C. R., Zerrenner, S. A., Verrone, M. A. G., \& Santos, S. D. (2006). A influência da educação financeira nas decisões de consumo e investimento dos indivíduos. Anais Seminário em Administração, 9.

Lusardi, A. (2007). Pension Plans and Financial Advice: Should Companies Follow IBM's Initiative?. Employee Benefit Plan Review, 62(1), 16-17.

Lusardi, A., \& Mitchell, O. S. (2007). Baby boomer retirement security: The roles of planning, financial literacy, and housing wealth. Journal of monetary Economics, 54(1), 205-224. DOI: https://doi.org/10.3386/w12585.

Lusardi, A. \& Mitchell, O.S. (2011). Financial literacy and retirement planning in the United States. Journal of Pension Economics and Finance, 10(4), 509-525.

Lusardi, A., Mitchell, O. S., \& Curto, V. (2010). Financial literacy among the young. Journal of consumer affairs, 44(2), 358-380. DOI: https://doi.org/10.1111/j.1745-6606.2010.01173.x.

Mandell, L. (2005). The connection between saving and financial literacy. National Credit Union Youth Week, $17-23$.

Mandell, L. (2008). Financial literacy of high school students. In: Xiao, J.J. (Ed.), Handbook of Consumer Finance Research. Springer, New York, pp. 163-183.

Mandell, L., \& Klein, L. S. (2007). Motivation and financial literacy. Financial Services Review, 16(2), 105-116.

Martins, J. P. (2004). Educação Financeira ao Alcance de Todos. São Paulo: Editora Fundamento Educacional.

Miotto, A. P. S., \& Parente, J. (2015). Antecedents and Consequences of Household Financial Management in Brazilian Lower-Middle-Class. Revista de Administração de Empresas, 55(1), 50-64. DOI: http://dx.doi. org/10.1590/S0034-759020150106 .

Mori, E., \& Lewis, A. (2001). Money in the contemporary Family. Nestle Family Monitor, 20, 3-21. 
Organization for Economic Co-Operation and Development - OECD (2009). Framework for the Development of Financial Literacy Baseline Surveys: A First International Comparative Analysis. OECD Working Papers on Finance, Insurance and Private Pensions, No. 1, OECD Publishing.

Oehler, A., \& Werner, C. (2008). Saving for retirement - a case for financial education in Germany and UK? An economic perspective. Journal of Consumer Policy, 31(3), 253-283. DOI: https://oi.org/10.1007/s10603008-9074-5.

O'Neill, B. (1992). Youth, money, and financial planning. Journal of home economics (USA).

Organization for Economic Co-Operation and Development - OECD. (2013). Financial literacy and inclusion: Results of OECD/INFE survey across countries and by gender. Paris, France: OECD Centre.

Perry, V. G. (2008). Is ignorance bliss? Consumer accuracy in judgments about credit ratings. Journal of Consumer Affairs, 42(2), 189-205. DOI: https://doi.org/10.1111/j.1745-6606.2008.00104.x.

Pires, D., Lima, O., Dalongaro, R., Sampaio, P., \& Silveira, J. (2013). Educação Financeira como Estratégia para Inclusão de Jovens na Bolsa de Valores. Tourism \& Management Studies, 3.

Potrich, A. C. G., Vieira, K. M., \& Kirch, G. (2015). Determinantes da Alfabetização Financeira: Análise da Influência de Variáveis Socioeconômicas e Demográficas. Revista Contabilidade \& Finanças, 26(69), 362377. DOI: http://dx.doi.org/10.1590/1808-057x201501040.

Pritchard, M. E. \& Myers, B. K. (1992). Consumer education: A partnership between schools and families. Journal of Consumer Education, 10, 38-43.

Robb, C. A. (2011). Financial knowledge and credit card behavior of college students. Journal of family and economic issues, 32(4), 690-698. DOI: https://doi.org/10.1007/s10834-011-9259-y.

Savoia, J. R. F., Saito, A. T., \& Santana, F. D. A. (2007). Paradigmas da educação financeira no Brasil. Revista de Administração Pública, 41(6), 1121-1141. DOI: http://dx.doi.org/10.1590/S0034-76122007000600006.

Shim, S., Barber, B. L., Card, N. A., Xiao, J. J., \& Serido, J. (2010). Financial socialization of first-year college students: The roles of parents, work, and education. Journal of Youth and Adolescence, 39 (12), 1457-1470. DOI: https://doi.org/10.1007/s10964-009-9432-x.

Silva, T. P. da, Dal Magro, C. B. Gorla, M. C., \& Nakamura, W. T. (2017). Financial education level of high school students and its economic reflections. Revista de Administração, 52(3), 285-303. DOI: https://doi. org/10.1016/j.rausp.2016.12.010

Vieira, S. F. A., Bataglia, R. T. M., \& Sereia, V. J. (2011). Educação financeira e decisões de consumo, investimento e poupança: uma análise dos alunos de uma universidade pública do norte do Paraná. Revista de Administração da Unimep, 9(3), 61-86. DOI: http://dx.doi.org/10.15600/rau.v9i3.345.

Webley, P., \& Nyhus, E. K. (2006). Parents' influence on children's future orientation and saving. Journal of Economic Psychology, 27(1), 140-164. DOI: https://doi.org/10.1016/j.joep.2005.06.016.

Worthington, A. C. (2006). Predicting financial literacy in Australia. Financial Services Review, 15(1), 59-79.

\section{Como citar este artigo}

Dal Magro, C. B.; Gorla, M. C.; Silva, T. P. da; \& Hein, N. (2018). O efeito da família no comportamento financeiro de adolescentes em escolas públicas. Revista de Contabilidade e Organizações, 12:e142534. DOI: http://dx.doi.org/10.11606/issn.1982-6486.rco.2018.142534 
APÊNDICE A

Tabela 7. Gênero e a influência da família na educação financeira

\begin{tabular}{|c|c|c|c|c|c|c|c|}
\hline \multicolumn{8}{|c|}{ Prestar Contas - Responsabilidade de prestar contas do uso do dinheiro para os pais ou companheiro (a): } \\
\hline Gênero & (1) & $(2)$ & (3) & (4) & & & \\
\hline M & $41,7 \%$ & $17,7 \%$ & $17,9 \%$ & $22,6 \%$ & & & \\
\hline $\mathrm{F}$ & $37,1 \%$ & $23,1 \%$ & $15,8 \%$ & $24,0 \%$ & & & \\
\hline Não informad. & $50,0 \%$ & $29,2 \%$ & $8,3 \%$ & $12,5 \%$ & & & \\
\hline \multicolumn{8}{|c|}{ Diálogo - Diálogo na hora de decidir a compra de um produto para o uso da família, normalmente: } \\
\hline Gênero & (1) & $(2)$ & (3) & (4) & & & \\
\hline M & $32,3 \%$ & $6,9 \%$ & $8,4 \%$ & $52,4 \%$ & & & \\
\hline $\mathrm{F}$ & $35,7 \%$ & $3,3 \%$ & $4,6 \%$ & $56,4 \%$ & & & \\
\hline Não informad. & $33,3 \%$ & $12,5 \%$ & $16,7 \%$ & $37,5 \%$ & & & \\
\hline \multicolumn{8}{|c|}{ Frequência - Com que frequência você conversa com os pais sobre dinheiro? } \\
\hline Gênero & (1) & (2) & (3) & (4) & & & \\
\hline $\mathrm{M}$ & $28,2 \%$ & $25,6 \%$ & $28,6 \%$ & $17,6 \%$ & & & \\
\hline $\mathrm{F}$ & $18,6 \%$ & $33,6 \%$ & $24,1 \%$ & $23,8 \%$ & & & \\
\hline Não informad. & $29,2 \%$ & $25,0 \%$ & $29,2 \%$ & $16,7 \%$ & & & \\
\hline \multicolumn{8}{|c|}{ Assunto - Qual assunto financeiro é mais questionado com a família: } \\
\hline Gênero & (1) & $(2)$ & (3) & (4) & $(5)$ & & \\
\hline M & $12,7 \%$ & $14,4 \%$ & $25,5 \%$ & $35,5 \%$ & $11,8 \%$ & & \\
\hline $\mathrm{F}$ & $9,4 \%$ & $14,1 \%$ & $33,0 \%$ & $34,3 \%$ & $9,3 \%$ & & \\
\hline Não informad. & $20,8 \%$ & $8,3 \%$ & $33,3 \%$ & $33,3 \%$ & $4,2 \%$ & & \\
\hline \multicolumn{8}{|c|}{ Referência - Caso você tenha algum conhecimento financeiro, como adquiriu? } \\
\hline Gênero & (1) & $(2)$ & (3) & (4) & $(5)$ & (6) & (7) \\
\hline M & $5,5 \%$ & $9,7 \%$ & $4,4 \%$ & $9,0 \%$ & $23,5 \%$ & $4,4 \%$ & $43,4 \%$ \\
\hline $\mathrm{F}$ & $4,6 \%$ & $6,6 \%$ & $5,7 \%$ & $9,2 \%$ & $25,4 \%$ & $0,9 \%$ & $47,5 \%$ \\
\hline Não informad. & $4,2 \%$ & $8,3 \%$ & $4,2 \%$ & $8,3 \%$ & $41,7 \%$ & $4,2 \%$ & $29,2 \%$ \\
\hline \multicolumn{8}{|c|}{ Autonomia - Como decido o que fazer com meu dinheiro? } \\
\hline Gênero & (1) & (2) & (3) & (4) & (5) & & \\
\hline M & $2,5 \%$ & $59,8 \%$ & $4,3 \%$ & $30,6 \%$ & $2,8 \%$ & & \\
\hline $\mathrm{F}$ & $4,9 \%$ & $52,4 \%$ & $2,8 \%$ & $36,6 \%$ & $3,4 \%$ & & \\
\hline Não informad. & $8,3 \%$ & $70,8 \%$ & $0,0 \%$ & $16,7 \%$ & $4,2 \%$ & & \\
\hline
\end{tabular}

Fonte: Elaborado pelos autores.

Nota: M - Masculino; F - Feminino. 
Tabela 8. Nível de ensino e a influência da família na educação financeira

\begin{tabular}{|c|c|c|c|c|c|c|c|}
\hline \multicolumn{8}{|c|}{ Prestar Contas - Responsabilidade de prestar contas do uso do dinheiro para os pais ou companheiro(a): } \\
\hline Nível Ensino & $(1)$ & $(2)$ & (3) & (4) & & & \\
\hline $1^{\circ}$ Ano & $34,0 \%$ & $23,3 \%$ & $17,2 \%$ & $25,5 \%$ & & & \\
\hline $2^{\circ}$ Ano & $40,1 \%$ & $19,7 \%$ & $16,4 \%$ & $23,8 \%$ & & & \\
\hline $3^{\circ}$ Ano & $44,3 \%$ & $19,2 \%$ & $16,8 \%$ & $19,6 \%$ & & & \\
\hline \multicolumn{8}{|c|}{ Diálogo - Diálogo na hora de decidir a compra de um produto para o uso da família, normalmente: } \\
\hline Nível Ensino & (1) & $(2)$ & (3) & (4) & & & \\
\hline $1^{\circ}$ Ano & $34,9 \%$ & $7,5 \%$ & $6,8 \%$ & $50,9 \%$ & & & \\
\hline $2^{\circ}$ Ano & $34,4 \%$ & $4,5 \%$ & $6,9 \%$ & $54,3 \%$ & & & \\
\hline $3^{\circ}$ Ano & $32,8 \%$ & $3,4 \%$ & $5,7 \%$ & $58,1 \%$ & & & \\
\hline \multicolumn{8}{|c|}{ Frequência - Com que frequência você conversa com os pais sobre dinheiro? } \\
\hline Nível Ensino & (1) & $(2)$ & (3) & (4) & & & \\
\hline $1^{\circ}$ Ano & $30,4 \%$ & $26,2 \%$ & $23,3 \%$ & $20,1 \%$ & & & \\
\hline $2^{\circ}$ Ano & $19,4 \%$ & $29,8 \%$ & $28,6 \%$ & $22,1 \%$ & & & \\
\hline $3^{\circ}$ Ano & $21,5 \%$ & $33,4 \%$ & $25,7 \%$ & $19,4 \%$ & & & \\
\hline \multicolumn{8}{|c|}{ Assunto - Qual assunto financeiro é mais questionado com a família: } \\
\hline Nível Ensino & $(1)$ & $(2)$ & $(3)$ & (4) & $(5)$ & & \\
\hline $1^{\circ}$ Ano & $14,6 \%$ & $14,6 \%$ & $26,9 \%$ & $35,4 \%$ & $8,5 \%$ & & \\
\hline $2^{\circ}$ Ano & $9,0 \%$ & $14,2 \%$ & $29,8 \%$ & $36,3 \%$ & $10,6 \%$ & & \\
\hline $3^{\circ}$ Ano & $10,6 \%$ & $13,6 \%$ & $31,7 \%$ & $31,9 \%$ & $12,3 \%$ & & \\
\hline \multicolumn{8}{|c|}{ Referência - Caso você tenha algum conhecimento financeiro, como adquiriu? } \\
\hline Nível Ensino & (1) & $(2)$ & (3) & (4) & $(5)$ & (6) & (7) \\
\hline $1^{\circ}$ Ano & $7,1 \%$ & $8,3 \%$ & $3,6 \%$ & $7,5 \%$ & $24,3 \%$ & $2,8 \%$ & $46,4 \%$ \\
\hline $2^{\circ}$ Ano & $4,9 \%$ & $7,1 \%$ & $5,1 \%$ & $10,1 \%$ & $22,3 \%$ & $2,8 \%$ & $47,8 \%$ \\
\hline $3^{\circ}$ Ano & $2,8 \%$ & $9,4 \%$ & $6,8 \%$ & $9,2 \%$ & $29,1 \%$ & $2,1 \%$ & $40,6 \%$ \\
\hline \multicolumn{8}{|c|}{ Autonomia - Como decido o que fazer com meu dinheiro? } \\
\hline Nível Ensino & (1) & $(2)$ & (3) & (4) & $(5)$ & & \\
\hline $1^{\circ}$ Ano & $4,2 \%$ & $55,0 \%$ & $4,7 \%$ & $31,8 \%$ & $4,3 \%$ & & \\
\hline $2^{\circ}$ Ano & $4,3 \%$ & $56,1 \%$ & $2,8 \%$ & $33,9 \%$ & $2,9 \%$ & & \\
\hline $3^{\circ}$ Ano & $2,6 \%$ & $57,2 \%$ & $3,2 \%$ & $34,9 \%$ & $2,1 \%$ & & \\
\hline
\end{tabular}

Fonte: Elaborado pelos autores. 
Tabela 9. Idade acima de série e o papel da família na educação financeira

\begin{tabular}{|c|c|c|c|c|c|c|c|}
\hline \multicolumn{8}{|c|}{ Prestar Contas - Responsabilidade de prestar contas do uso do dinheiro para os pais ou companheiro(a): } \\
\hline Idade acima da Série & $(1)$ & $(2)$ & (3) & (4) & & & \\
\hline Sim & $46,1 \%$ & $15,4 \%$ & $15,4 \%$ & $23,0 \%$ & & & \\
\hline Não & $37,9 \%$ & $21,9 \%$ & $17,0 \%$ & $23,2 \%$ & & & \\
\hline \multicolumn{8}{|c|}{ Diálogo - Diálogo na hora de decidir a compra de um produto para o uso da família, normalmente: } \\
\hline Idade acima da Série & (1) & (2) & (3) & (4) & & & \\
\hline $\operatorname{Sim}$ & $35,0 \%$ & $7,9 \%$ & $6,8 \%$ & $50,4 \%$ & & & \\
\hline Não & $33,9 \%$ & $4,4 \%$ & $6,4 \%$ & $55,2 \%$ & & & \\
\hline \multicolumn{8}{|c|}{ Frequência - Com que frequência você conversa com os pais sobre dinheiro? } \\
\hline Idade acima da Série & (1) & (2) & (3) & (4) & & & \\
\hline $\operatorname{Sim}$ & $25,7 \%$ & $22,8 \%$ & $27,6 \%$ & $23,8 \%$ & & & \\
\hline Não & $22,6 \%$ & $31,4 \%$ & $25,9 \%$ & $20,1 \%$ & & & \\
\hline \multicolumn{8}{|c|}{ Assunto - Qual assunto financeiro é mais questionado com a família: } \\
\hline Idade acima da Série & (1) & (2) & (3) & (4) & (5) & & \\
\hline Sim & $11,7 \%$ & $14,1 \%$ & $26,8 \%$ & $34,7 \%$ & $12,7 \%$ & & \\
\hline Não & $11,0 \%$ & $14,2 \%$ & $30,1 \%$ & $34,9 \%$ & $9,9 \%$ & & \\
\hline \multicolumn{8}{|c|}{ Referência - Caso você tenha algum conhecimento financeiro, como adquiriu? } \\
\hline Idade acima da Série & (1) & (2) & (3) & (4) & $(5)$ & (6) & (7) \\
\hline $\operatorname{Sim}$ & $4,5 \%$ & $8,2 \%$ & $5,2 \%$ & $9,1 \%$ & $25,3 \%$ & $2,4 \%$ & $45,4 \%$ \\
\hline Não & $7,3 \%$ & $7,6 \%$ & $4,9 \%$ & $9,2 \%$ & $22,5 \%$ & $3,3 \%$ & $45,3 \%$ \\
\hline \multicolumn{8}{|c|}{ Autonomia - Como decido o que fazer com meu dinheiro? } \\
\hline Idade acima da Série & (1) & (2) & (3) & (4) & $(5)$ & & \\
\hline $\operatorname{Sim}$ & $4,0 \%$ & $56,1 \%$ & $3,3 \%$ & $33,9 \%$ & $2,8 \%$ & & \\
\hline Não & $3,0 \%$ & $56,1 \%$ & $4,3 \%$ & $32,2 \%$ & $4,3 \%$ & & \\
\hline
\end{tabular}

Fonte: Elaborado pelos autores. 
Tabela 10. Idade e a influência da família na educação financeira

\begin{tabular}{|c|c|c|c|c|c|c|c|}
\hline \multicolumn{8}{|c|}{ Prestar Contas - Responsabilidade de prestar contas do uso do dinheiro para os pais ou companheiro(a): } \\
\hline Idade & (1) & $(2)$ & (3) & (4) & & & \\
\hline Menor 14 & $33,3 \%$ & $66,7 \%$ & $0 \%$ & $0 \%$ & & & \\
\hline Entre 14 e 16 & $34,6 \%$ & $22,9 \%$ & $17,6 \%$ & $25,0 \%$ & & & \\
\hline Entre 17 e 20 & $45,5 \%$ & $17,7 \%$ & $15,7 \%$ & $21,1 \%$ & & & \\
\hline Acima de 20 & $40,0 \%$ & $10,0 \%$ & $30,0 \%$ & $20,0 \%$ & & & \\
\hline \multicolumn{8}{|c|}{ Diálogo - Diálogo na hora de decidir a compra de um produto para o uso da família, normalmente: } \\
\hline Idade & (1) & $(2)$ & (3) & (4) & & & \\
\hline Menor 14 & $50,0 \%$ & $0 \%$ & $16,7 \%$ & $33,3 \%$ & & & \\
\hline Entre 14 e 16 & $34,5 \%$ & $5,0 \%$ & $6,9 \%$ & $53,6 \%$ & & & \\
\hline Entre 17 e 20 & $33,5 \%$ & $5,1 \%$ & $5,8 \%$ & $55,6 \%$ & & & \\
\hline Acima de 20 & $40,0 \%$ & $10,0 \%$ & $20,0 \%$ & $30,0 \%$ & & & \\
\hline \multicolumn{8}{|c|}{ Frequência - Com que frequência você conversa com os pais sobre dinheiro? } \\
\hline Idade & (1) & $(2)$ & (3) & (4) & & & \\
\hline Menor 14 & $33,3 \%$ & $16,7 \%$ & $16,7 \%$ & $33,3 \%$ & & & \\
\hline Entre 14 e 16 & $23,3 \%$ & $30,7 \%$ & $25,8 \%$ & $20,2 \%$ & & & \\
\hline Entre 17 e 20 & $22,7 \%$ & $28,9 \%$ & $26,8 \%$ & $21,6 \%$ & & & \\
\hline Acima de 20 & $50,0 \%$ & $10,0 \%$ & $30,0 \%$ & $10,0 \%$ & & & \\
\hline \multicolumn{8}{|c|}{ Assunto - Qual assunto financeiro é mais questionado com a família: } \\
\hline Idade & (1) & $(2)$ & (3) & (4) & $(5)$ & & \\
\hline Menor 14 & $33,3 \%$ & $0 \%$ & $50,0 \%$ & $16,7 \%$ & $0 \%$ & & \\
\hline Entre 14 e 16 & $11,0 \%$ & $14,4 \%$ & $29,3 \%$ & $36,7 \%$ & $8,7 \%$ & & \\
\hline Entre 17 e 20 & $11,3 \%$ & $14,0 \%$ & $29,6 \%$ & $32,5 \%$ & $12,6 \%$ & & \\
\hline Acima de 20 & $0 \%$ & $10,0 \%$ & $30,0 \%$ & $50,0 \%$ & $10,0 \%$ & & \\
\hline \multicolumn{8}{|c|}{ Referência - Caso você tenha algum conhecimento financeiro, como adquiriu? } \\
\hline Idade & (1) & $(2)$ & (3) & (4) & $(5)$ & (6) & (7) \\
\hline Menor 14 & $0,0 \%$ & $16,7 \%$ & $16,7 \%$ & $16,7 \%$ & $33,3 \%$ & $0,0 \%$ & $16,7 \%$ \\
\hline Entre 14 e 16 & $5,2 \%$ & $7,7 \%$ & $4,3 \%$ & $8,8 \%$ & $23,1 \%$ & $2,7 \%$ & $48,1 \%$ \\
\hline Entre 17 e 20 & $4,9 \%$ & $8,4 \%$ & $6,0 \%$ & $9,4 \%$ & $26,6 \%$ & $2,4 \%$ & $42,3 \%$ \\
\hline Acima de 20 & $0,0 \%$ & $20,0 \%$ & $0,0 \%$ & $10,0 \%$ & $30,0 \%$ & $0,0 \%$ & $40,0 \%$ \\
\hline \multicolumn{8}{|c|}{ Autonomia - Como decido o que fazer com meu dinheiro? } \\
\hline Idade & (1) & $(2)$ & (3) & (4) & $(5)$ & & \\
\hline Menor 14 & $16,7 \%$ & $66,7 \%$ & $0,0 \%$ & $16,7 \%$ & $0,0 \%$ & & \\
\hline Entre 14 e 16 & $4,7 \%$ & $55,3 \%$ & $3,2 \%$ & $33,7 \%$ & $3,0 \%$ & & \\
\hline Entre 17 e 20 & $2,7 \%$ & $57,0 \%$ & $3,8 \%$ & $33,3 \%$ & $3,2 \%$ & & \\
\hline Acima de 20 & $0,0 \%$ & $50,0 \%$ & $0,0 \%$ & $50,0 \%$ & $0,0 \%$ & & \\
\hline
\end{tabular}


Tabela 11. Morar com os pais e a influência da família na educação financeira

Prestar Contas - Responsabilidade de prestar contas do uso do dinheiro para os pais ou companheiro(a):

\begin{tabular}{|c|c|c|c|c|c|c|c|}
\hline Mora com os pais & $(1)$ & $(2)$ & (3) & (4) & & & \\
\hline Sim & $38,4 \%$ & $21,0 \%$ & $16,9 \%$ & $23,6 \%$ & & & \\
\hline Não & $49,2 \%$ & $16,9 \%$ & $14,8 \%$ & $19,1 \%$ & & & \\
\hline \multicolumn{8}{|c|}{ Diálogo - Diálogo na hora de decidir a compra de um produto para o uso da família, normalmente: } \\
\hline Mora com os pais & $(1)$ & $(2)$ & (3) & (4) & & & \\
\hline Sim & $33,8 \%$ & $4,8 \%$ & $6,6 \%$ & $54,8 \%$ & & & \\
\hline Não & $37,2 \%$ & $7,7 \%$ & $5,5 \%$ & $49,7 \%$ & & & \\
\hline \multicolumn{8}{|c|}{ Frequência - Com que frequência você conversa com os pais sobre dinheiro? } \\
\hline Mora com os pais & $(1)$ & $(2)$ & (3) & (4) & & & \\
\hline Sim & $21,9 \%$ & $30,0 \%$ & $26,8 \%$ & $21,2 \%$ & & & \\
\hline Não & $35,5 \%$ & $26,8 \%$ & $20,8 \%$ & $16,9 \%$ & & & \\
\hline \multicolumn{8}{|c|}{ Assunto - Qual assunto financeiro é mais questionado com a família: } \\
\hline Mora com os pais & $(1)$ & $(2)$ & (3) & (4) & $(5)$ & & \\
\hline Sim & $10,5 \%$ & $13,8 \%$ & $29,6 \%$ & $35,7 \%$ & $10,3 \%$ & & \\
\hline Não & $16,4 \%$ & $17,5 \%$ & $28,4 \%$ & $26,2 \%$ & $11,5 \%$ & & \\
\hline \multicolumn{8}{|c|}{ Referência - Caso você tenha algum conhecimento financeiro, como adquiriu? } \\
\hline Mora com os pais & $(1)$ & $(2)$ & $(3)$ & (4) & $(5)$ & $(6)$ & (7) \\
\hline Sim & $5,0 \%$ & $8,3 \%$ & $5,2 \%$ & $8,9 \%$ & $23,9 \%$ & $2,3 \%$ & $46,4 \%$ \\
\hline Não & $5,5 \%$ & $6,6 \%$ & $4,4 \%$ & $10,9 \%$ & $32,2 \%$ & $4,9 \%$ & $35,5 \%$ \\
\hline \multicolumn{8}{|c|}{ Autonomia - Como decido o que fazer com meu dinheiro? } \\
\hline Mora com os pais & (1) & (2) & (3) & (4) & $(5)$ & & \\
\hline $\operatorname{Sim}$ & $3,5 \%$ & $56,4 \%$ & $3,4 \%$ & $33,4 \%$ & $3,2 \%$ & & \\
\hline Não & $6,6 \%$ & $52,5 \%$ & $3,8 \%$ & $35,0 \%$ & $2,2 \%$ & & \\
\hline
\end{tabular}

Fonte: Elaborado pelos autores.

Tabela 12. Gênero e o comportamento para poupança e conhecimento financeiro

\begin{tabular}{cccccc}
\hline \multicolumn{5}{c}{ Objetivo - Em relação à forma de administrar meus recursos financeiros, costumo: } \\
\hline Gênero & $(1)$ & $(2)$ & $(3)$ & $(4)$ & \\
M & $25,8 \%$ & $18,4 \%$ & $38,0 \%$ & $17,8 \%$ & \\
F & $28,1 \%$ & $13,8 \%$ & $38,0 \%$ & $20,1 \%$ & \\
Não informad. & $37,5 \%$ & $8,3 \%$ & $29,2 \%$ & $25,0 \%$ & $(5)$ \\
\hline \multicolumn{6}{c}{ Perfil - Em relação ao meu perfil financeiro, me considero: } \\
\hline Gênero & $(1)$ & $(2)$ & $(3)$ & $(4)$ & $20,2 \%$ \\
M & $5,9 \%$ & $20,3 \%$ & $13,7 \%$ & $40,0 \%$ & $17,8 \%$ \\
F & $6,5 \%$ & $25,0 \%$ & $7,4 \%$ & $43,3 \%$ & $12,5 \%$ \\
Não informad. & $16,7 \%$ & $20,8 \%$ & $12,5 \%$ & $37,5 \%$ & $(5)$ \\
\hline \multicolumn{7}{c}{ Gênero } & Conhecimento - Como considera seu nível de conhecimento financeiro & $(4)$ & $6,3 \%$ \\
M & $(1)$ & $(2)$ & $(3)$ & $11,4 \%$ & $4,5 \%$ \\
F & $6,4 \%$ & $30,7 \%$ & $45,2 \%$ & $9,9 \%$ & $20,8 \%$ \\
\hline
\end{tabular}

Fonte: Elaborado pelos autores. 
Tabela 13. Nível de ensino e o comportamento para poupança e conhecimento financeiro

\begin{tabular}{|c|c|c|c|c|c|}
\hline \multicolumn{6}{|c|}{ Objetivo - Em relação à forma de administrar meus recursos financeiros, costumo: } \\
\hline Nível de Ensino & (1) & (2) & (3) & (4) & \\
\hline $1^{\circ}$ Ano & $30,9 \%$ & $17,7 \%$ & $31,8 \%$ & $19,6 \%$ & \\
\hline $2^{\circ}$ Ano & $24,5 \%$ & $17,3 \%$ & $40,2 \%$ & $17,9 \%$ & \\
\hline $3^{\circ}$ Ano & $27,2 \%$ & $11,5 \%$ & $40,9 \%$ & $20,4 \%$ & \\
\hline \multicolumn{6}{|c|}{ Perfil - Em relação ao meu perfil financeiro, me considero: } \\
\hline Nível de Ensino & (1) & (2) & (3) & (4) & $(5)$ \\
\hline $1^{\circ}$ Ano & $7,5 \%$ & $27,6 \%$ & $12,5 \%$ & $36,1 \%$ & $16,3 \%$ \\
\hline $2^{\circ}$ Ano & $5,8 \%$ & $20,8 \%$ & $9,3 \%$ & $45,1 \%$ & $19,0 \%$ \\
\hline $3^{\circ}$ Ano & $6,0 \%$ & $20,4 \%$ & $10,0 \%$ & $42,3 \%$ & $21,3 \%$ \\
\hline \multicolumn{6}{|c|}{ Conhecimento - Como considera seu nível de conhecimento financeiro } \\
\hline Nível de Ensino & (1) & (2) & (3) & (4) & $(5)$ \\
\hline $1^{\circ}$ Ano & $5,2 \%$ & $36,8 \%$ & $41,8 \%$ & $8,9 \%$ & $7,3 \%$ \\
\hline $2^{\circ}$ Ano & $5,2 \%$ & $33,6 \%$ & $45,8 \%$ & $10,0 \%$ & $5,4 \%$ \\
\hline $3^{\circ}$ Ano & $6,8 \%$ & $28,5 \%$ & $47,4 \%$ & $13,6 \%$ & $3,8 \%$ \\
\hline
\end{tabular}

Fonte: Elaborado pelos autores.

Tabela 14. Idade acima da série e o comportamento para poupança e conhecimento financeiro

\begin{tabular}{|c|c|c|c|c|c|}
\hline \multicolumn{6}{|c|}{ Objetivo - Em relação à forma de administrar meus recursos financeiros, costumo: } \\
\hline Idade acima da Série & $(1)$ & $(2)$ & (3) & (4) & \\
\hline Sim & $28,2 \%$ & $16,8 \%$ & $35,5 \%$ & $19,5 \%$ & \\
\hline Não & $26,9 \%$ & $15,6 \%$ & $38,5 \%$ & $19,0 \%$ & \\
\hline \multicolumn{6}{|c|}{ Perfil - Em relação ao meu perfil financeiro, me considero: } \\
\hline Idade acima da Série & (1) & $(2)$ & (3) & (4) & $(5)$ \\
\hline Sim & $4,9 \%$ & $24,7 \%$ & $10,3 \%$ & $40,1 \%$ & $20,1 \%$ \\
\hline Não & $6,7 \%$ & $22,3 \%$ & $10,5 \%$ & $42,0 \%$ & $18,6 \%$ \\
\hline \multicolumn{6}{|c|}{ Conhecimento - Como considera seu nível de conhecimento financeiro } \\
\hline Idade acima da Série & (1) & (2) & (3) & (4) & (5) \\
\hline Sim & $6,5 \%$ & $33,1 \%$ & $45,8 \%$ & $9,2 \%$ & $5,4 \%$ \\
\hline Não & $5,4 \%$ & $33,2 \%$ & $44,9 \%$ & $11,0 \%$ & $5,5 \%$ \\
\hline
\end{tabular}

Fonte: Elaborado pelos autores. 
Tabela 15. Idade e o comportamento para poupança e conhecimento financeiro

\begin{tabular}{|c|c|c|c|c|c|}
\hline \multicolumn{6}{|c|}{ Objetivo - Em relação à forma de administrar meus recursos financeiros, costumo: } \\
\hline Idade & (1) & (2) & (3) & (4) & \\
\hline Menor 14 & $0 \%$ & $0 \%$ & $66,7 \%$ & $33,3 \%$ & \\
\hline Entre 14 e 16 & $26,8 \%$ & $17,9 \%$ & $36,9 \%$ & $18,3 \%$ & \\
\hline Entre 17 e 20 & $27,8 \%$ & $13,3 \%$ & $39,0 \%$ & $19,8 \%$ & \\
\hline Acima de 20 & $20,0 \%$ & $20,0 \%$ & $30,0 \%$ & $30,0 \%$ & \\
\hline \multicolumn{6}{|c|}{ Perfil - Em relação ao meu perfil financeiro, me considero: } \\
\hline Idade & (1) & (2) & (3) & (4) & $(5)$ \\
\hline Menor 14 & $33,3 \%$ & $16,7 \%$ & $33,3 \%$ & $16,7 \%$ & $0 \%$ \\
\hline Entre 14 e 16 & $6,9 \%$ & $23,1 \%$ & $10,6 \%$ & $42,2 \%$ & $17,2 \%$ \\
\hline Entre 17 e 20 & $5,5 \%$ & $22,2 \%$ & $10,0 \%$ & $41,3 \%$ & $21,1 \%$ \\
\hline Acima de 20 & $10,0 \%$ & $30,0 \%$ & $20,0 \%$ & $30,0 \%$ & $10,0 \%$ \\
\hline \multicolumn{6}{|c|}{ Conhecimento - Como considera seu nível de conhecimento financeiro } \\
\hline Idade & (1) & (2) & (3) & (4) & (5) \\
\hline Menor 14 & $0 \%$ & $16,7 \%$ & $33,3 \%$ & $16,7 \%$ & $33,3 \%$ \\
\hline Entre 14 e 16 & $4,8 \%$ & $35,3 \%$ & $44,0 \%$ & $9,5 \%$ & $6,3 \%$ \\
\hline Entre 17 e 20 & $6,7 \%$ & $30,5 \%$ & $46,5 \%$ & $11,9 \%$ & $4,3 \%$ \\
\hline Acima de 20 & $0 \%$ & $40,0 \%$ & $40,0 \%$ & $10,0 \%$ & $10,0 \%$ \\
\hline
\end{tabular}

Fonte: Elaborado pelos autores.

Tabela 16. Morar com os pais e o comportamento para poupança e conhecimento financeiro

\begin{tabular}{|c|c|c|c|c|c|}
\hline \multicolumn{6}{|c|}{ Objetivo - Em relação à forma de administrar meus recursos financeiros, costumo: } \\
\hline Mora com os pais & (1) & (2) & (3) & (4) & \\
\hline Sim & $27,1 \%$ & $16,4 \%$ & $37,8 \%$ & $18,6 \%$ & \\
\hline Não & $27,3 \%$ & $10,4 \%$ & $38,8 \%$ & $23,5 \%$ & \\
\hline \multicolumn{6}{|c|}{ Perfil - Em relação ao meu perfil financeiro, me considero: } \\
\hline Mora com os pais & (1) & (2) & (3) & (4) & (5) \\
\hline Sim & $6,4 \%$ & $23,1 \%$ & $10,5 \%$ & $41,4 \%$ & $18,6 \%$ \\
\hline Não & $6,0 \%$ & $19,1 \%$ & $9,3 \%$ & $44,3 \%$ & $21,3 \%$ \\
\hline \multicolumn{6}{|c|}{ Conhecimento - Como considera seu nível de conhecimento financeiro } \\
\hline Mora com os pais & (1) & (2) & (3) & (4) & (5) \\
\hline Sim & $5,4 \%$ & $33,5 \%$ & $45,2 \%$ & $10,7 \%$ & $5,2 \%$ \\
\hline Não & $7,7 \%$ & $30,1 \%$ & $44,3 \%$ & $9,8 \%$ & $8,2 \%$ \\
\hline
\end{tabular}

Fonte: Elaborado pelos autores. 
Tabela 17. Teste de diferença de médias ANOVA do comportamento para poupança dos adolescentes entre os clusters que determinaram a influência da família na educação financeira

\begin{tabular}{|c|c|c|c|c|c|}
\hline Variável dependente & (I) Cluster & (J) Cluster & $\begin{array}{c}\text { Diferença } \\
\text { média (I-J) }\end{array}$ & Erro Padrão & Sig. \\
\hline \multirow{6}{*}{ Objetivo } & \multirow{2}{*}{1} & 2 & $-0,0972$ & 0,0602 & 0,240 \\
\hline & & 3 & $0,1541^{*}$ & 0,0615 & $0,033^{*}$ \\
\hline & \multirow{2}{*}{2} & 1 & 0,0972 & 0,0602 & 0,240 \\
\hline & & 3 & $0,2513^{*}$ & 0,0589 & $0,000^{*}$ \\
\hline & \multirow{2}{*}{3} & 1 & $-0,1541^{*}$ & 0,0615 & $0,033^{*}$ \\
\hline & & 2 & $-0,2513^{*}$ & 0,0589 & $0,000^{*}$ \\
\hline \multirow{6}{*}{ Perfil } & \multirow{2}{*}{1} & 2 & $-0,1941^{*}$ & 0,0667 & $0,010^{*}$ \\
\hline & & 3 & $0,2178^{*}$ & 0,0682 & $0,004 *$ \\
\hline & \multirow{2}{*}{2} & 1 & $0,1941^{*}$ & 0,0667 & $0,010^{*}$ \\
\hline & & 3 & $0,4119^{*}$ & 0,0653 & $0,000^{*}$ \\
\hline & \multirow{2}{*}{3} & 1 & $-0,2178^{*}$ & 0,0682 & $0,004 *$ \\
\hline & & 2 & $-0,4119^{*}$ & 0,0653 & $0,000^{*}$ \\
\hline
\end{tabular}

Fonte: Elaborado pelos autores. 